\title{
Una novela criminal
}

Erik Del Ángel Landeros (1) https://orcid.org/0000-(0002-2749-2119

Universidad Nacional Autónoma de México, México

erikdelangellan@gmail.com

Jorge Volpi, Una novela criminal, México, Alfaguara, 2018.

A fines de los 70, en Francia, François Bédarida y otros historiadores se preguntaron cómo llamarle a la etapa histórica después de la Segunda Guerra Mundial, ya que en ese momento no se podía considerar como Historia contemporánea. Decidieron denominarle "historia del tiempo presente”. Décadas atrás, en el mismo país, los historiadores de los Annales también repararon en la necesidad de estudiar el presente y crearon el concepto "historia inmediata". Precisamente en Francia, pero en el siglo XXI, Nicolás Sarkozy, le dio un vuelco a la historia que presenta Jorge Volpi, el episodio Cassez-Vallarta; el cual cuenta con suficientes fuentes para poderse escribir desde el punto de vista de la Historia, a pesar de haber acontecido hace apenas una década y aún estar activo en algunos capítulos. No me cabe duda que Jacques Le Goff, Jean Lacouture o Marc Bloch estarían de acuerdo con esto, pero no sólo ellos, sino posiblemente cualquier historiador que leyera Una novela criminal.

No obstante, para algunos sectores dentro de la Historia, reseñar un libro con acontecimientos demasiado recientes puede ser cuestionable, tal vez, no más que hacerlo sobre una obra en formato novela, aunque en los salones de clases de la disciplina se repita, tal vez sin mucha convicción, que la literatura también es una fuente historiográfica. En este caso, la novela sin ficción o fáctica de Volpi funciona como una investigación histórica tal cual, a pesar 
de que no use un aparato crítico de Historia o las Ciencias Sociales. No obstante, sí utiliza las herramientas metodológicas de un historiador, a saber:

Esta novela sin ficción se basa de manera sustancial en los expedientes judiciales de Florence Cassez y la familia Vallarta, así como en la transcripción de discursos, declaraciones y entrevistas de los protagonistas de la historia... Al ser ésta una novela y no un ensayo, decidí no indicar entre corchetes las partes omitidas. En mi descargo sólo puedo añadir que he hecho hasta lo imposible para estos cortes jamás alteren la intención o el sentido que los declarantes querían darle a sus dichos (pp. 481, 482).

El autor hace explícito lo que el lector, con ojos de historiador, constata en el libro, un manejo minucioso y serio de un sinfín de fuentes de todo tipo: documentales, al más puro estilo rankeano, de historia oral, audiovisuales y de fuentes secundarias, citando, como los buenos historiadores, las obras realizadas por otros sobre el tema investigado (en este caso trabajos periodísticos en su mayoría). Aunque Volpi explica poco sobre la manera en que obtuvo sus fuentes (no está obligado a ello), se entiende que, por un lado, fue posible gracias a su contacto con los protagonistas y al ser un reconocido literato, por otro y seguramente, a las leyes de transparencia y acceso a la información de nuestro país. Situación que ha provocado que los archivos documentales, fuente principal del historiador, sean consultables casi a la par que sucede el hecho estudiado. Este elemento ha sido aprovechado por juristas, científicos sociales, economistas, periodistas y poco por los historiadores, al preferir etapas históricas de más largo alcance a las actuales. En suma, Una novela criminal aborda un tema, pronto entraremos en ello, que se beneficia por la existencia de múltiples fuentes, lo cual permite una afortunada crítica y contrastación de las mismas.

Ahí el otro punto que refirió el autor, cómo maneja sus fuentes. Al ser una novela, Volpi se siente con la obligación de aclarar que respetó el testimonio de los sujetos y la información de los documentos, que no hay ficción. Para un historiador estaría de más mencionarlo, o decir cómo llegó a conclusiones, a qué elementos dio más peso (aunque sería 
deseable que lo hicieran); pero sobre todo, el novelista dice qué hizo con los silencios, con los vacíos, esos enemigos inmisericordes del historiador. El recurso es el mismo para el historiador o el literato, conjeturar, suponer, siempre aclarándolo:

Si bien me esforcé por contrastar y confirmar los testimonios contradictorios, muchas veces no me quedó otra salida que decantarme por la versión que juzgué más verosímil. Para llenar los incontables vacíos o lagunas, en ocasiones me arriesgué a conjeturar- a imaginar- escenas o situaciones que carecen de sustento en documentos, pruebas o testimonios oficiales: cuando así ocurre, lo asiento de manera explícita para evitar que una ficción elaborada por mí pudiera ser confundida con las ficciones tramadas por las autoridades (p.11).

Una novela criminal atraviesa las entrañas del sistema de procuración de justicia y judicial del país. Mediante el caso emblemático de Cassez e Israel Vallarta se muestra la constante de dicho sistema: corrupción, falta de independencia entre poderes, violación a los derechos humanos, teniendo a la tortura (tema de larga data sí tratado en la historiografía) como el mecanismo de prueba que sostiene a todo el aparato judicial. Pero el eje de Volpi no empieza ni acaba en un caso de tribunales, no es monotemático, lo que muchos historiadores sí somos en nuestros trabajos. Utiliza su historia para ir a lo particular, la biografía de muchos personajes, y después a lo general, como el conflicto bilateral entre México y Francia, en el que el temperamento de sus mandatarios determina el curso de las relaciones internacionales. Seguramente ahí reside la grandeza literaria de la obra. El autor, gracias a estos dotes, logra acercarse a una historia total, de nuevo los Annales, que captura muchos aspectos del periodo 2005-2013 (aunque diversos hilos llegan hasta 2017) en México y otro tanto en Francia.

El libro está organizado de manera cronológica primordialmente, estructura cada vez menos socorrida en las novelas. A través de cinco capítulos se conocen los casos de las víctimas de secuestro, hasta donde las fuentes y los declarantes permiten. También la vida y trayectoria de Cassez y su novio y las circunstancias que los llevaron a la posición de presuntos 
secuestradores. Como ondas expansivas, se muestra la forma en que el caso toca trágicamente a las familias de ambos. En estas partes se retrata a profundidad las formas de vida de algunos estratos sociales, esencialmente los capitalinos. Se pone un foco a una historia de migración, que sirve de modelo para conocer esta circunstancia. Se aprecian las características culturales de dos naciones por medio de su interacción y muchas veces de su choque.

Se ahonda, evidentemente, en lo que se denominó el montaje televisivo, ocurrido el 9 de diciembre de 2005. Quedan al desnudo prácticas, tanto de la entonces Agencia Federal de Investigaciones, a cargo de Genaro García Luna, como del papel de los medios de comunicación, no sólo del noticiero de Loret de Mola y sus reporteros, sino de otros periodistas que son los que dan los pasos iniciales para que se descubran los vicios del caso. A lo largo del libro también se retrata a los tipos de prensa en el país, su peso, en algunos casos, y su poco peso, en otros, tanto en la formación de opiniones, como en la presión para que los actos de autoridad se revisen.

Una y otra vez se muestran fabricaciones de culpables, manipulación de evidencia, influencia indebida sobre víctimas y testigos, y tortura, tortura siempre, arraigada como método de "procuración de justicia”. Las narrativas e invenciones de las autoridades se modifican, se adulteran, se vuelven más fantasiosas e irreales que cualquier ficción. Con cada modificación, se crean más culpables que son tragados por el Poder Judicial, se pone una loza más pesada a los presuntos delincuentes captados en cadena nacional en el rancho Las Chinitas.

El caso toma real importancia cuando Nicolás Sarkozy, quien presta atención a Cassez gracias a políticos de la localidad donde vive la familia de ésta, decide incluir el caso de su connacional en la agenda bilateral con México. En la medida en que el asunto se mediatiza y las sociedades toman partido por sus paisanos, tanto Felipe Calderón como el mandatario galo chocan. Sus temperamentos producen una crisis diplomática. En el texto se retrata cómo 
operan las cancillerías y sus agentes. La información y los testimonios permiten reconstruir una Historia diplomática y de las Relaciones Internacionales que ya desearíamos muchos historiadores dedicados a ello. Asimismo, se hace patente el poder de García Luna en el gabinete de Calderón. Ayudando a entender la dinámica del Gobierno en lo que llamó lucha contra la delincuencia organizada.

Otro de los aciertos de Volpi es mostrar el modo en que opera el Poder Judicial, cómo funcionan jueces, magistrados y ministros. Las diferencias entre ellos. La mayoría de los jueces tienen en las carpetas de investigación de las procuradurías las sentencias de sus casos, no importando que en los juicios se señalen faltas al debido proceso. La novela permite ver las luchas entre ministros para resolver sus casos, las sutilezas que se vuelven fundamentales. Una Suprema Corte de Justicia de la Nación asediada por intereses y por los egos de sus propios integrantes. La obra logra superar los tecnicismos legales, incluir su sustancia y hacerlos digeribles. Se retrata una etapa histórica en la que iniciará en México el cambio de sistema penal inquisitivo a uno acusatorio.

El autor no se propone ni quiere calificar a Cassez y Vallarta como culpables o inocentes, a pesar de que su información da mucha luz para sacar conclusiones. Prefiere dejarlas al lector. Se siente obligado a ello para tratar de ser objetivo. Esta es una de las diferencias con los trabajos historiográficos, normalmente, los historiadores presentan sus conclusiones con los elementos que tienen, es parte de las aportaciones que se tratan de hacer, proponer explicaciones sobre procesos sociales. Por otro lado, Volpi lo dice y queda claro en el libro, hay una fuente faltante, la pieza que permitiría cerrar el rompecabezas y que, tal vez, sí hubiera provocado una conclusión de su parte: el testimonio de los secuestrados. Sus declaraciones cambiaron tanto, se volvieron tan contradictorias por la aparente manipulación 
de la procuraduría, que las hacen inservibles para llegar a la verdad. Así que todavía hay un eslabón fundamental en esta historia y la ventana para que desde cualquier disciplina se siga investigando y escribiendo sobre el caso.

Una novela criminal es la investigación más acabada sobre el episodio Cassez-Vallarta, fuente obligada para quienes quieran estudiar el tema en el futuro. Volpi no publica un avance parcial de su investigación, un extracto, como normalmente lo habían hecho los periodistas por las premuras naturales de su ejercicio que evitan la "maduración histórica”. Él esperó a reunir la suficiente cantidad de fuentes, confrontarlas y presentar su propuesta. Citó documentos completos, en detrimento de la fluidez y estética requerida para una novela, punto que más se ha criticado por los especialistas en literatura, pero que, para los historiadores, al contrario, abona al rigor y solidez de la investigación que realiza.

El interés principal de Volpi es acercarse a la verdad, antes que a la belleza. Para ello, utiliza la esencia básica de la metodología histórica, si esta es útil para aproximarse a la verdad, en un sentido de trascendencia, no debe regateársele la condición de investigación de Historia por muchos fundamentalismos académicos o teóricos que se puedan esgrimir.

Ya se ha dicho que la investigación cuenta con una abundancia de fuentes de todo tipo, las cuales parecen ser tratadas de manera crítica y rigurosa. Sin embargo, debido a esta heterogeneidad y a las temáticas tan diversas que se cruzan, posiblemente, haya varios resquicios que se omitieron o que se dieron por válidos. Esta posibilidad tendría cabida también por la formación de Volpi como literato, no como especialista en el manejo y lectura de fuentes tan disímbolas. Aunque esto es apenas una hipótesis, que sólo un estudio con las mismas fuentes podría comprobar o refutar.

Otro riesgo de hacer historia actual, inmediata o del tiempo presente, como lo hace el autor, es la implicación personal que se tiene al dialogar con los protagonistas. Puede que la 
Erik Del Ángel Landeros

empatía o la animadversión que se puede generar con el sujeto estudiado, más que condicionar las conclusiones, modifique la forma en que se dialoga, se busca, se encuentra. Riesgo al que no están exentos otros científicos que hacen estudios sociales sobre acontecimientos de su tiempo.

Secuencia. E-ISSN 2395-8464 